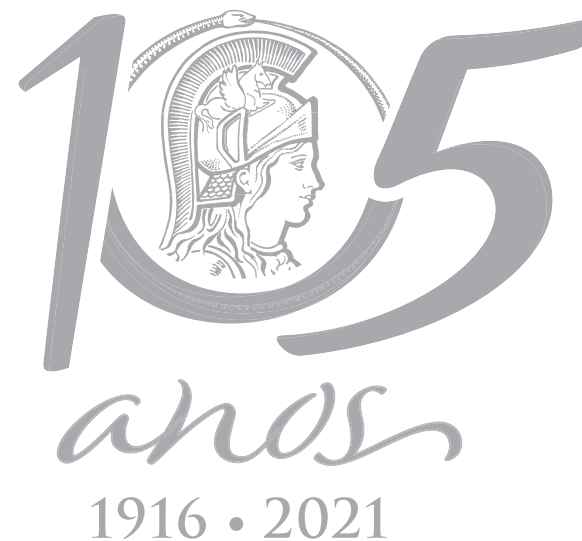

$1916 \cdot 2021$

\title{
Swimming exercise and diphenyl diselenide- supplemented diet modulate cerebral cortical and striatal GABA uptake in aged rats
}

\author{
ANA PAULA PESARICO, JOSÉ L. CECHELLA, CRISTINA W. NOGUEIRA \& SUZAN G. \\ ROSA
}

\begin{abstract}
Aging is characterized by several neurochemical modifications involving structural proteins and neurotransmitters. Exercise has been recognized as an enhancer of overall health; whereas, diphenyl diselenide (PhSe) ${ }_{2}$ has been reported to have antioxidant, anti-inflammatory, and neuroprotective effects in rodents. A combination of pharmacological and non-pharmacological interventions has been proposed to prevent the aging effects. This study aimed to determine the swimming exercise and (PhSe) dietary supplementation synergic effects on the $\left[{ }^{3} \mathrm{H}\right] \mathrm{\gamma}$-aminobutyric acid (GABA) uptake in aged rats. Male Wistar rats (24 months) received $1 \mathrm{ppm}$ of (PhSe)$)_{2}$ supplemented in the standard chow for 4 weeks. Rats were subjected to swimming training (20 min per day for 4 weeks). After 4 weeks, the $\left.{ }^{3} \mathrm{H}\right]$ GABA uptake was determined in samples of cerebral cortex and striatum of rats. The results of the present study demonstrate that the association of (PhSe) ${ }_{2}$-supplemented diet and swimming exercise was effective against the decrease of cerebral cortical and striatal $\left[{ }^{3} \mathrm{H}\right] \mathrm{GABA}$ uptake in aged rats. The association of (PhSe) ${ }_{2}$ dietary supplementation with swimming exercise modulated the GABA uptake in cerebral structures of aged rats.
\end{abstract}

Key words: aged, $y$-aminobutyric acid, swimming exercise, organoselenium, supplementation.

\section{INTRODUCTION}

The aging is a result of changes in synaptic activity reflecting both functional and structural cell derangement (Morrison \& Hof 1997). Evidence has been found to suggest that the loss of neurotransmitters, their receptors, and responsiveness to neurotransmitters are manifestations of neurological aging and age-related disorders (Marczynski 1998, El Idrissi 2008). Among these the most abundant inhibitory neurotransmitter in the brain, y-aminobutyric acid (GABA) (Araki et al. 1996), is highlighted. Alterations in cognition, motor, and neural functions are reasons of researchers attempt to explain biological mechanisms of aging and interventions to delay aging and promote healthy longevity.

Exercise, a non-pharmacological intervention, has significant clinical relevance; both clinical and preclinical studies suggest that exercise can postpone detrimental aspects of aging (Mercken et al. 2012, Erdos et al. 2007, Lefevre et al. 2009, Samorajski et al. 1985). Specifically, aerobic exercise is an intervention that produces positive impacts in aged individuals with neurological disorders. Many mechanisms have been discussed to explain these positive impacts, including the increase in cerebral blood flow and neurotrophic factors, modulation of neurotransmitter release, and 
structural changes in the central nervous system (CNS) (Mackay et al. 2017, Mang et al. 2013, Colcombe et al. 2006).

However, many of the elderly population with functional ability do not adapt to high exercise levels, which motivate the development of pharmacological interventions that would synergize with exercise. In addition, the dietary supplementation has been used to improve physical performance and attenuate the stress caused by exercise. Some studies indicate that somewhere between half and three-quarters of American adults use dietary supplements (Bailey et al. 2011, 2013).

Selenium is an essential micronutrient for a wide range of living organisms, including the human being, which plays a role in the neurotransmissionand redoxstatus(FairweatherTait et al. 2011, Brigelius-Flohe \& Flohe 2017, Vogt et al. 2018). It has been demonstrated that organoselenium compounds as a source of supplements have beneficial effects in different rodent models, for example, the p,p'-methoxyldiphenyl diselenide dietary supplementation enhanced memory by modulation of oxidative stress and acetylcholinesterase activity; whereas, the p-chloro analogue-supplemented in the diet induced a satiating action (Bortolatto et al. 2015, Sartori Oliveira et al. 2016, Pinton et al. 2013). In addition to the beneficial effects in adult rodents, we have demonstrated neuroprotective, memory enhancer, and antiinflammatory actions of diphenyl diselenide (PhSe) ${ }_{2}$ dietary supplementation in aged rats (Cechella et al. 2014, Leite et al. 2016).

Based on the considerations above, this study aimed to determine the effects of swimming exercise and a diet supplemented with (PhSe) ${ }_{2}$ on the GABA uptake in the cerebral structures, cortex and striatum, of aged rats.

\section{MATERIALS AND METHODS}

\section{Animals}

The experiments were carried out using adult ( 4 months, 200-250g) and old (24 months, 700-750g) male Wistar rats. The animals were obtained from a local breeding colony and were kept in a separate air-conditioned $\left(22 \pm 2{ }^{\circ} \mathrm{C}\right)$ room, on a 12-h light/12-h dark cycle with lights turned on at 7:00 a.m. The animals were housed in separate plastic cages with free access to food and water. All manipulations were carried out between 8:00 a.m. and 4:00 p.m. The animals were used according to the guidelines of the Committee on Care and Use of Experimental Animal Resources, the Federal University of Santa Maria, Brazil (\#5394050115) and following the Guide for the Care and Use of Laboratory Animals (1996, published by National Academy Press, 2101 Constitution Ave. NW, Washington, DC 20055, USA).

\section{Drugs}

(PhSe) ${ }_{2}$ was prepared and characterized in our laboratory by the method previously described (Paulmier 2013). Analysis of the ${ }^{1} \mathrm{H}$ nuclear magnetic resonance spectroscopy and

${ }^{13} \mathrm{C}$ nuclear magnetic resonance spectroscopy spectra showed analytical and spectroscopic data in full agreement with its assigned structure. The chemical purity of (PhSe) ${ }_{2}$ (99.9\%) was determined by gas chromatography coupled to mass spectrometry. L-[ $\left.{ }^{3} \mathrm{H}\right] \mathrm{GABA}$ (specific activity $40 \mathrm{Ci} / \mathrm{mmol}$ ) was purchased from Amersham International, UK. All other chemicals were obtained from analytical grade and standard commercial suppliers.

\section{Experimental design}

The experimental design of this study is shown in Fig. 1. The male Wistar rats were separated into five groups $(n=3-4)$ as follows: group 


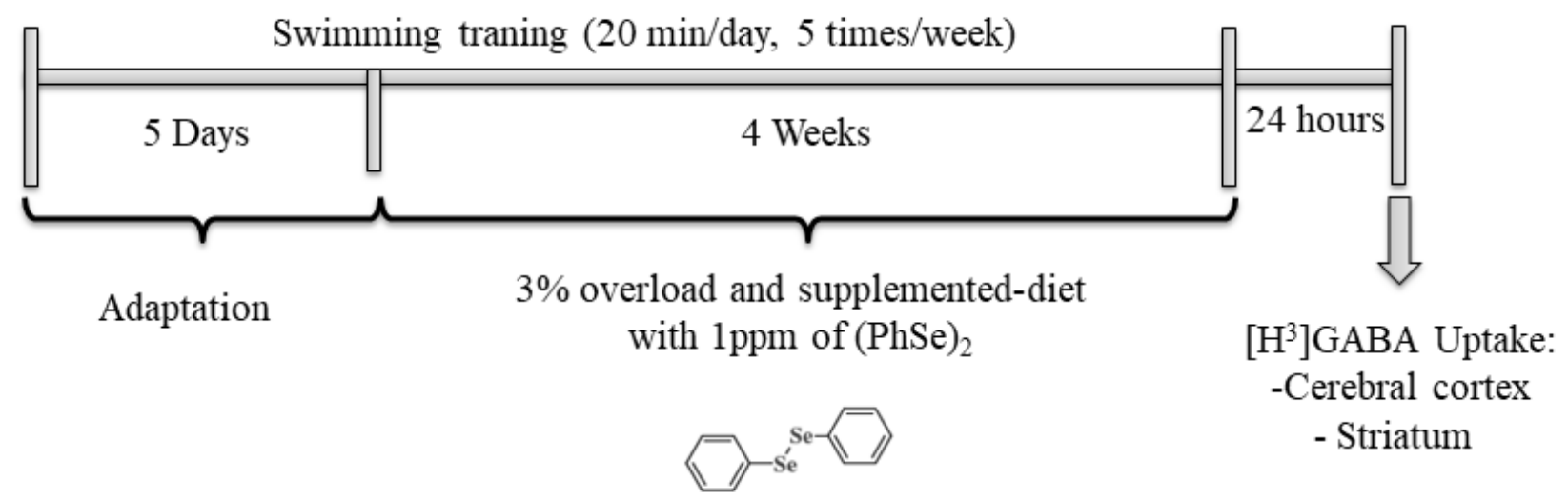

$(\mathrm{PhSe})_{2}$

Figure 1. Schematic representation of the experimental design of this study.

I- adult sedentary (non-exercised) rats treated with a standard diet; group II- old sedentary (non-exercised) rats treated with a standard diet; group III- old sedentary (non-exercised) rats treaded with $1 \mathrm{ppm}$ (PhSe) $)_{2}$-supplemented diet, group IV- old exercised rats (subjected to a swimming training protocol and treated with a standard diet) and group $\mathrm{V}$ - old exercised (subjected to a swimming training protocol) and treated with $1 \mathrm{ppm}$ (PhSe) ${ }_{2}$ - supplemented diet rats.

The supplementation began after the period of adaptation to swimming training. The animals were fed daily for 4 weeks with a standard diet chow or a standard chow supplemented with $1 \mathrm{ppm}$ of $(\mathrm{PhSe})_{2}$. The preparation and concentration of (PhSe) ${ }_{2}$ supplemented standard chow were based on our previous published study (Cechella et al. 2014). The standard diet was pulverized with ethyl alcohol, whereas the supplemented diet was pulverized with $(\mathrm{PhSe})_{2}$ (1 mg of (PhSe) ${ }_{2} / 1000 \mathrm{~g}$ standard chow) dissolved in ethyl alcohol $(1 \mathrm{mg} / 100 \mathrm{ml})$. The standard and supplemented diets were stored at room temperature for $3 \mathrm{~h}$ to evaporate the alcohol and then kept at $4^{\circ} \mathrm{C}$ for no more than 1 week.

The exercise training was based on the protocol described by Ravi Kiran et al. (2004). The rats from the exercised groups performed a pre-training of 20 min daily for five days. After this period of adaptation, rats were subjected to the swimming training exercise with a workload (3\% of body weight), sessions of $20 \mathrm{~min}$, five days per week/ four weeks. The swimming training occurred at a water temperature of $32 \pm 1{ }^{\circ} \mathrm{C}$ between 1:00 p.m. and 3:00 p.m. The animals in the sedentary groups (I, II, and III groups) were placed in the bottom of a separate tank with shallow water $(5 \mathrm{~cm})$ at $32 \pm 1{ }^{\circ} \mathrm{C}$, without the workload, that consists of adapting to water. At the end of the exercise training period, all animals were towel dried before being returned to their cages.

The pre-training, $20 \mathrm{~min}$ daily for five days, was performed without load to progressively adapt the rats to the water environment and avoid stress of swimming. Furthermore, the rats were observed to record symptoms of fatigue or all other signal of abnormalities.

\section{Ex vivo assay}

Immediately after the end of the last swimming exercise session, the rats were killed by decapitation and the cerebral cortices and striatum were removed to perform the $\left[{ }^{3} \mathrm{H}\right] \mathrm{GABA}$ uptake assay according to previous studies (Thomazi et al. 2004, Schweigert et al. 2005). Any anesthetics were used for this procedure, 
because they may act through a GABA mechanism and interfere with the final results (Brohan \& Goudra 2017, Cheng \& Brunner 1980).

The slices $(0.4 \mathrm{~mm})$ were obtained by transversal cuts of the striatum and cerebral cortices using Mcllwain chopper. Experiments were made in triplicates. Slices were preincubated for 15 min at $37{ }^{\circ} \mathrm{C}$ in a Hank's balanced salt solution (HBSS) containing (in $\mathrm{mM}$ ): 137 $\mathrm{NaCl}, 0.63 \mathrm{Na}_{2} \mathrm{HPO}_{4}, 4.17 \mathrm{NaHCO}_{3}, 5.36 \mathrm{KCl}, 0.44$ $\mathrm{KH}_{2} \mathrm{PO}_{4}, 1.26 \mathrm{CaCl}_{2}, 0.41 \mathrm{MgSO}_{4}, 0.49 \mathrm{MgCl}_{2}$ and 1.11 glucose, adjusted to $\mathrm{pH}$ 7.2. After $15 \mathrm{~min}$ of preincubation, the uptake assay was performed by adding $8.3 \mathrm{nM}\left[{ }^{3} \mathrm{H}\right] \mathrm{GABA}$. Incubation was stopped after $7 \mathrm{~min}$, with three ice-cold washes of $1 \mathrm{ml}$ HBSS, immediately followed by the addition of $0.5 \mathrm{~N} \mathrm{NaOH}$, which was then kept overnight. An aliquot of $10 \mu \mathrm{l}$ was removed for protein determination. Unspecific uptake was measured using the same protocol described above, with differences in the temperature $\left(4^{\circ} \mathrm{C}\right)$ and medium composition (choline chloride instead of sodium chloride). $\mathrm{Na}^{+}$-dependent uptake was considered as the difference between the total uptake and the unspecific uptake. Incorporated radioactivity was measured using a liquid scintillation counter, Wallac 1409. Results were expressed as pmol $\left[{ }^{3} \mathrm{H}\right] \mathrm{GABA}$ uptake/mg protein. $\min ^{-1}$.

\section{Protein determination}

Protein concentration was determined by the method previously described by Bradford (1976) using bovine serum albumin $(1 \mathrm{mg} / \mathrm{ml})$ as a standard.

\section{Statistical analysis}

Data were analyzed by One-way ANOVA of variance followed by the post-hoc analysis Newman-Keuls test. Descriptive statistics data were expressed as the mean (s) \pm S.E.M. Probability values less than 0.05 were considered as statistically significant. The normality was analyzed by the D'Agostino test and all data present normal distribution.

\section{RESULTS}

The one-way analysis of $\left[{ }^{3} \mathrm{H}\right] \mathrm{GABA}$ uptake revealed a significant effect in the cerebral cortices $\left(F_{(4,18)}=4.901, p=0.0111\right)$ and striatum $\left(F_{(4,18)}=6.248, p=0.0042\right)$. Post hoc analysis indicated a decrease in the $\left[{ }^{3} \mathrm{H}\right] \mathrm{GABA}$ uptake in the cerebral cortices (Fig. 2a) and striatum (Fig. $2 b$ ) of aged rats when compared with the adult control group, $p<0.05$ and $p<0.01$, respectively. Combined treatment with ( $\mathrm{PhSe}$ 2 $_{2}$ supplemented diet and swimming exercise was effective against the decrease in the cortical and striatal $\left[{ }^{3} \mathrm{H}\right] \mathrm{GABA}$ uptake in aged rats $(p<0.05)$.

The effects of isolated therapies on $\left[{ }^{3} \mathrm{H}\right] \mathrm{GABA}$ uptake were partial and structure-dependent; whereas (PhSe)-supplemented diet partially restored the decrease in $\left.{ }^{3} \mathrm{H}\right] \mathrm{GABA}$ uptake in the cerebral cortices $(p<0.05)$, swimming exercise was partially effective in the striatum of aged rats ( $p<0.05$, Fig. $2 \mathrm{a}$ and $2 \mathrm{~b}$ ).

\section{DISCUSSION}

The present study reveals the effect of swimming exercise and a diet supplemented with $1 \mathrm{ppm}$ of (PhSe) ${ }_{2}$ on the $\left[{ }^{3} \mathrm{H}\right] \mathrm{GABA}$ uptake in the cerebral cortex and striatum of aged rats. The results demonstrate a reduction of GABA uptake in the cerebral cortex and striatum of aged rats and that the combination of swimming exercise and (PhSe) ${ }_{2}$ dietary supplementation normalized the GABA uptake in both cerebral structures of aged rats.

It has been widely demonstrated that the functioning of the brain depends critically on the precise balance between excitatory and 

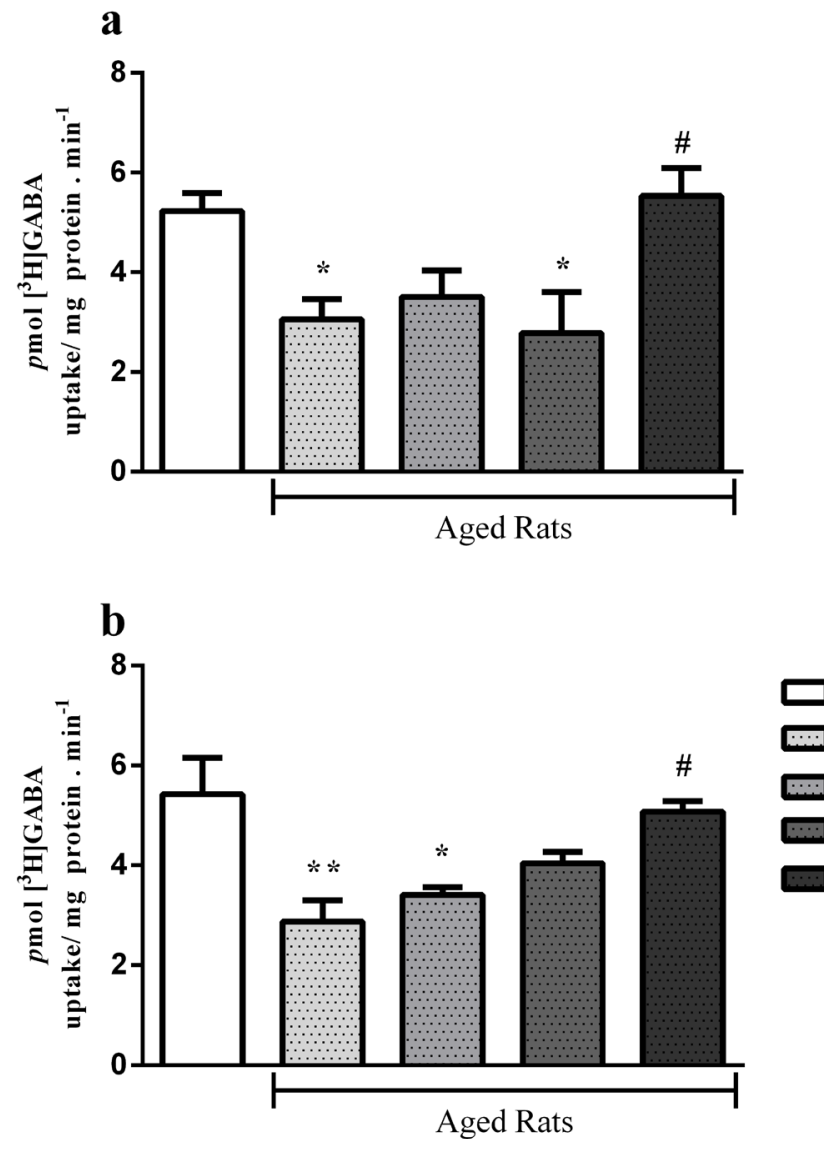

inhibitory neurotransmitter systems (Turrigiano \& Nelson 2004, Wefelmeyer et al. 2015). Excitation is mediated via glutamate and inhibition is mediated via GABA, which regulates the degree of glutamatergic excitation (Bak et al. 2006).

The GABA and glutamate are the main neurotransmitters in the basal ganglia, a group of several subcortical structures, among them the striatum, involved in the integration and processing of sensorimotor, cognitive, and limbic information. In addition, the striatum receives projections from virtually all areas of the cerebral cortex (Galvan et al. 2006). Therefore, striatum and cerebral cortex have played an important role in regulating central neurotransmitter systems in aging.

In the present study, we have focused our attention on GABA, the major inhibitory neurotransmitter in the brain, because aging
Figure 2. Effects of a (PhSe) ${ }_{2}$ supplemented diet (1 ppm for 4 weeks) and swimming exercise on the GABA uptake in the cerebral cortex a) and striatum b) of aged rats. Values are expressed as the mean $\pm \operatorname{SEM}(n=3-4$ rats per group). Data were analyzed by one-way ANOVA followed by the Newman-Keul's test for post hoc comparison when appropriate. ${ }^{*} p<0.05$ and ${ }^{* *} p<0.01$ as compared with the adult control rats; " $p<0.05$ as compared with the aged control rats.
Adult Control

Aged Control

$\left(\mathrm{PhSe}_{2}\right)$

Exercise

$\left(\mathrm{PhSe}_{2}\right)+$ Exercise changes associated with the GABAergic system function involve some aspects, among them the decrease in GABA levels (BanaySchwartz et al. 1989), GABA receptor subunits (Gutierrez et al. 1994), GABA release, and glutamic acid decarboxylase (GAD) activity (El Idrissi 2008). These age-related changes could contribute to increasing excitability in the CNS and the decreased GABA uptake could be a compensatory mechanism of neuroprotection in the brain structures, such as the cerebral cortex and striatum. It is important to note that in addition to the projection of the cerebral cortex to the striatum (McGeorge \& Faull 1989), there is a positive correlation between GABA uptake in the cerebral cortices and striatum in this study. Furthermore, the combination of swimming exercise and dietary (PhSe), supplementation was effective against the decrease in the GABA 
uptake, suggesting that this combined therapy contributes to neuroprotection.

Some studies have demonstrated the effect of (PhSe) ${ }_{2}$ administration in the GABA system. For example, the anxiolytic-like action of (PhSe) in rats is related, in part, to its modulation of the GABA system (Rosa et al. 2016, Ghisleni et al. 2008). With regard to exercise, it also modulates the GABA system, Barzroodi Pour et al. (2019) reported anti-epileptic and neuroprotective effects of exercise that were attributed to the modulation of GABA disinhibition. Exercise has been also associated with the control of hypertension and cardiac hypertrophy, which was partially mediated by modulating the GABA system (Li et al. 2018).

Besides, it has been previously reported the beneficial effects of a combination of swimming exercise and a diet supplemented with (PhSe) in the CNS, among them (1) the effectiveness in improving short-term and long-term memory as well as spatial learning (Cechella et al. 2014), (2) to promote neuroprotection, reducing apoptosis and glial cell activation in the hypothalamus of old rats (Leite et al. 2016), and (3) to modulate the levels of pro- and anti-inflammatory cytokines (Leite et al. 2015). Furthermore, this combination was effective against age-related changes in the hepatic metabolism of rats (Heck et al. 2016). Therefore, we suggest that, at least in part, the modulation of the cerebral cortical and striatal GABA uptake can contribute to the beneficial effects of (PhSe) ${ }_{2}$-supplemented diet and swimming exercise in aged rats.

We also suggest a relationship between the GABA system and oxidative stress, which is supported for two reasons: (1) both exercise and (PhSe) ${ }_{2}$ are antioxidants in the brain (de Souza et al. 2019, Solovyev 2015) and (2) Palmeira et al. (1993) demonstrated that after membrane lipid peroxidation, a decrease in the uptake of GABA was observed. Thus, the combination of swimming exercise and $(\mathrm{PhSe})_{2}$ dietary supplementation decreased oxidative stress and, consequently, increased the uptake of GABA. However, we assume that the lack of studies about oxidative stress in the cerebral cortex and striatum is a limitation of the present study.

Another important consideration is that Ravi Kiran et al. (2004) classified the intensity of swimming performed in the present study as a moderate (3\% of body weight) aerobic exercise. In this study, the authors used 3 exercise intensities, moderate, low (2\% of body weight), and heavy ( $5 \%$ of body weight). Evidence indicates that moderate intensity aerobic exercise enhanced cognitive function and memory (Wang \& Holsinger 2018) and alleviates the development of depression-like behaviors (Wu et al. 2017).

In conclusion, the results of the present study demonstrated the combined neuroprotective action of swimming exercise and (PhSe) ${ }_{2}$ dietary supplementation by modulating the decrease of GABA uptake in the cerebral cortex and striatum of aged rats.

\section{Acknowledgments}

We gratefully acknowledge Universidade Federal de Santa Maria (UFSM), Fundação de Amparo à Pesquisa do Estado do Rio Grande do Sul (FAPERGS) (2239-2551/14) and Conselho Nacional de Desenvolvimento Científico e Tecnológico (CNPq) (441405/2014-2) for the financial support. C.W.N. is recipient of CNPq fellowship.

\section{REFERENCES}

ARAKI T, KATO H, FUJIWARA T \& ITOYAMA Y. 1996. Regional age-related alterations in cholinergic and GABAergic receptors in the rat brain. Mech Ageing Dev 88: 49-60.

BAILEY RL, GAHCHE JJ, LENTINO CV, DWYER JT, ENGEL JS, THOMAS PR, BETZ JM, SEMPOS CT \& PICCIANO MF. 2011. Dietary supplement use in the United States, 2003-2006. J Nutr 141: 261-266. 
BAILEY RL, GAHCHE JJ, MILLER PE, THOMAS PR \& DWYER JT. 2013. Why US adults use dietary supplements. JAMA Intern Med 173: 355-361.

BAK LK, SCHOUSBOE A \& WAAGEPETERSEN HS. 2006. The glutamate/GABA-glutamine cycle: aspects of transport, neurotransmitter homeostasis and ammonia transfer. J Neurochem 98: 641-653.

BANAY-SCHWARTZ M, LAJTHA A \& PALKOVITS M. 1989. Changes with aging in the levels of amino acids in rat CNS structural elements. I. Glutamate and related amino acids. Neurochem Res 14: 555-562.

BARZROODI POUR M, BAYAT M, GOLAB F, EFTEKHARZADEH M, KATEBI M, SOLEIMANI M \& KARIMZADEH F. 2019. The effect of exercise on GABA signaling pathway in the model of chemically induced seizures. Life Sci 232: 116667.

BORTOLATTO CF, HECK SO, ZBOROWSKI VA, GAI BM, NETO JS \& NOGUEIRA CW. 2015. Evidence for the contribution of multiple mechanisms in the feeding pattern of rats exposed to p-chloro-diphenyl diselenide-supplemented diets. Physiol Behav 151: 298-307.

BRADFORD MM. 1976. A rapid and sensitive method for the quantitation of microgram quantities of protein utilizing the principle of protein-dye binding. Anal Biochem 72: 248-254.

BRIGELIUS-FLOHE R \& FLOHE L. 2017. Selenium and redox signaling. Arch Biochem Biophys 617: 48-59.

BROHAN J \& GOUDRA BG. 2017. The Role of GABA Receptor Agonists in Anesthesia and Sedation. CNS Drugs 31: 845-856.

CECHELLA JL, LEITE MR, ROSARIO AR, SAMPAIO TB \& ZENI G. 2014. Diphenyl diselenide-supplemented diet and swimming exercise enhance novel object recognition memory in old rats. Age (Dordr) 36: 9666.

CHENG S-C \& BRUNNER EA. 1980. Does GABA have a role in anesthesia? Brain Res Bull 5: 909-912.

COLCOMBE SJ, ERICKSON KI, SCALF PE, KIM JS, PRAKASH R, MCAULEY E, ELAVSKY S, MARQUEZ DX, HU L \& KRAMER AF. 2006. Aerobic exercise training increases brain volume in aging humans. J Gerontol A Biol Sci Med Sci 61: 1166-1170.

DE SOUZA RF, DE MORAES SRA, AUGUSTO RL, DE FREITAS ZANONA A, MATOS D, AIDAR FJ \& DA SILVEIRA ANDRADE-DA-COSTA BL. 2019. Endurance training on rodent brain antioxidant capacity: A meta-analysis. Neurosci Res 145: 1-9.

EL IDRISSI A. 2008. Taurine improves learning and retention in aged mice. Neurosci Lett 436: 19-22.

ERDOS B, BROXSON CS, LANDA T, SCARPACE PJ, LEEUWENBURGH C, ZHANG Y \& TUMER N. 2007. Effects of life-long caloric restriction and voluntary exercise on age-related changes in levels of catecholamine biosynthetic enzymes and angiotensin 1 receptors in the rat adrenal medulla and hypothalamus. Exp Gerontol 42: 745-752.

FAIRWEATHER-TAIT SJ, BAO Y, BROADLEY MR, COLLINGS R, FORD D, HESKETH JE \& HURST R. 2011. Selenium in human health and disease. Antioxid Redox Signal 14: 1337-1383.

GALVAN A, KUWAJIMA M \& SMITH Y. 2006. Glutamate and GABA receptors and transporters in the basal ganglia: what does their subsynaptic localization reveal about their function? Neuroscience 143: 351-375.

GHISLENI G, KAZLAUCKAS V, BOTH FL, PAGNUSSAT N, MIORANZZA S, ROCHA JB, SOUZA DO \& PORCIUNCULA LO. 2008. Diphenyl diselenide exerts anxiolytic-like effect in Wistar rats: putative roles of GABAA and $5 \mathrm{HT}$ receptors. Prog Neuropsychopharmacol Biol Psychiatry 32: 1508-1515.

GUTIERREZ A, KHAN ZU, MORRIS SJ \& DE BLAS AL. 1994. Agerelated decrease of GABAA receptor subunits and glutamic acid decarboxylase in the rat inferior colliculus. J Neurosci 14: 7469-7477.

HECK SO, FULCO BC, QUINES CB, OLIVEIRA CE, LEITE MR, CECHELLA JL \& NOGUEIRA CW. 2016. Combined Therapy With Swimming Exercise and a Diet Supplemented With Diphenyl Diselenide Is Effective Against Age-Related Changes in the Hepatic Metabolism of Rats. J Cell Biochem 118: 1574-1582.

LEFEVRE M, REDMAN LM, HEILBRONN LK, SMITH JV, MARTIN CK, ROOD JC, GREENWAY FL, WILLIAMSON DA, SMITH SR \& RAVUSSIN E. 2009. Caloric restriction alone and with exercise improves CVD risk in healthy non-obese individuals. Atherosclerosis 203: 206-213.

LEITE MR, CECHELLA JL, MANTOVANI AC, DUARTE MM, NOGUEIRA CW \& ZENI G. 2015. Swimming exercise and diphenyl diselenide-supplemented diet affect the serum levels of pro- and anti-inflammatory cytokines differently depending on the age of rats. Cytokine 71: 119-123.

LEITE MR, CECHELLA JL, PINTON S, NOGUEIRA CW \& ZENI G. 2016. A diphenyl diselenide-supplemented diet and swimming exercise promote neuroprotection, reduced cell apoptosis and glial cell activation in the hypothalamus of old rats. Exp Gerontol 82: 1-7.

LI HB, HUO CJ, SU Q, LI X, BAI J, ZHU GQ \& KANG YM. 2018. Exercise Training Attenuates Proinflammatory Cytokines, Oxidative Stress and Modulates Neurotransmitters in the Rostral Ventrolateral Medulla of Salt-Induced Hypertensive Rats. Cell Physiol Biochem 48: 1369-1381.

MACKAY CP, KUYS SS \& BRAUER SG. 2017. The Effect of Aerobic Exercise on Brain-Derived Neurotrophic Factor in People 
with Neurological Disorders: A Systematic Review and Meta-Analysis. Neural Plast 2017: 4716197.

MANG CS, CAMPBELL KL, ROSS CJ \& BOYD LA. 2013. Promoting neuroplasticity for motor rehabilitation after stroke: considering the effects of aerobic exercise and genetic variation on brain-derived neurotrophic factor. Phys Ther 93: 1707-1716.

MARCZYNSKI TJ. 1998. GABAergic deafferentation hypothesis of brain aging and Alzheimer's disease revisited. Brain Res Bull 45: 341-379.

MCGEORGE AJ \& FAULL RL. 1989. The organization of the projection from the cerebral cortex to the striatum in the rat. Neuroscience 29: 503-537.

MERCKEN EM, CARBONEAU BA, KRZYSIK-WALKER SM \& DE CABO R. 2012. Of mice and men: the benefits of caloric restriction, exercise, and mimetics. Ageing Res Rev 11: 390-398.

MORRISON JH \& HOF PR. 1997. Life and death of neurons in the aging brain. Science 278: 412-419.

PALMEIRA CM, SANTOS MS, CARVALHO AP \& OLIVEIRA CR. 1993. Membrane lipid peroxidation induces changes in gamma-[3H]aminobutyric acid transport and calcium uptake by synaptosomes. Brain Res 609: 117-123.

PAULMIER C. 2013. Selenium Reagents \& Intermediates in Organic Synthesis. Elsevier.

PINTON S, BRUNING CA, SARTORI OLIVEIRA CE, PRIGOL M \& NOGUEIRA CW. 2013. Therapeutic effect of organoselenium dietary supplementation in a sporadic dementia of Alzheimer's type model in rats. J Nutr Biochem 24: 311-317.

RAVI KIRAN T, SUBRAMANYAM MV \& ASHA DEVI S. 2004. Swim exercise training and adaptations in the antioxidant defense system of myocardium of old rats: relationship to swim intensity and duration. Comp Biochem Physiol B Biochem Mol Biol 137: 187-196.

ROSA SG, QUINES CB, STANGHERLIN EC \& NOGUEIRA CW. 2016. Diphenyl diselenide ameliorates monosodium glutamate induced anxiety-like behavior in rats by modulating hippocampal BDNF-Akt pathway and uptake of GABA and serotonin neurotransmitters. Physiol Behav 155: 1-8.

SAMORAJSKI T, DELANEY C, DURHAM L, ORDY JM, JOHNSON JA \& DUNLAP WP. 1985. Effect of exercise on longevity, body weight, locomotor performance, and passive-avoidance memory of C57BL/6J mice. Neurobiol Aging 6: 17-24.
SARTORI OLIVEIRA CE, PINTON S, DA ROCHA JT, GAI BM \& NOGUEIRA CW. 2016. The hypolipidemic action of a diet supplemented with p,p'-methoxyl-diphenyl diselenide is not directly related to its antioxidant property. Can J Physiol Pharmacol 94: 662-668.

SCHWEIGERT ID, DE OLIVEIRA DL, SCHEIBEL F, DA COSTA F, WOFCHUK ST, SOUZA DO \& PERRY ML. 2005. Gestational and postnatal malnutrition affects sensitivity of young rats to picrotoxin and quinolinic acid and uptake of GABA by cortical and hippocampal slices. Brain Res Dev Brain Res 154: 177-185.

SOLOVYEV ND. 2015. Importance of selenium and selenoprotein for brain function: From antioxidant protection to neuronal signalling. J Inorg Biochem 153: 1-12.

THOMAZI AP, GODINHO GF, RODRIGUES IM, SCHWALM FD, FRIZZO ME, MORIGUCHI E, SOUZA DO \& WOFCHUKST. 2004. Ontogenetic profile of glutamate uptake in brain structures slices from rats: sensitivity to guanosine. Mech Ageing Dev 125: 475-481.

TURRIGIANO GG \& NELSON SB. 2004. Homeostatic plasticity in the developing nervous system Nat Rev Neurosci 5: 97-107.

VOGT AG ET AL. 2018. Organoselenium group is critical for antioxidant activity of 7-chloro-4-phenylselenylquinoline. Chem Biol Interact 282: 7-12.

WANG R \& HOLSINGER RMD. 2018. Exercise-induced brainderived neurotrophic factor expression: Therapeutic implications for Alzheimer's dementia. Ageing Res Rev 48: 109-121.

WEFELMEYER W, CATTAERT D \& BURRONE J. 2015. Activitydependent mismatch between axo-axonic synapses and the axon initial segment controls neuronal output. Proc Natl Acad Sci USA 112: 9757-9762.

WU CC, HUNG CJ, LIN SY, WANG YY, CHANG CY, CHEN WY, LIAO SL, RAUNG SL, YANG CP \& CHEN CJ. 2017. Treadmill exercise alleviated prenatal buprenorphine exposure-induced depression in rats. Neurochem Int 110: 91-100. 


\section{How to cite}

PESARICO AP, CECHELLA JL, NOGUEIRA CW \& ROSA SG. 2022. Swimming exercise and diphenyl diselenide-supplemented diet modulate cerebral cortical and striatal GABA uptake in aged rats. An Acad Bras Cienc 94: e20200844. DOI 10.1590/0001-3765202220200844.

Manuscript received on June 8, 2020;

accepted for publication on January 21, 2021

\section{ANA PAULA PESARICO}

https://orcid.org/0000-0001-7608-0578

\section{JOSÉ L. CECHELLA}

https://orcid.org/0000-0001-5266-3824

\section{CRISTINA W. NOGUEIRA}

https://orcid.org/0000-0003-2950-3632

\section{SUZAN G. ROSA}

https://orcid.org/0000-0002-1832-982X

Universidade Federal de Santa Maria, Centro de Ciências Naturais e Exatas, Departamento de Bioquímica e Biologia Molecular, Laboratório de Síntese, Reatividade e Avaliação Farmacológica e Toxicológica de Organocalcogênios, Av. Roraima, 1000, Cidade Universitária, Camobi, 97105-900 Santa Maria, RS, Brazil

Correspondence to: Ana Paula Pesarico, Suzan Gonçalves Rosa E-mail:anappesarico@gmail.com,suzanrosa@hotmail.com

\section{Author contributions}

Ana P. Pesarico and Suzan G. Rosa: performed all neurochemistry studies and wrote the manuscript; José L. Cechella: carried out experimental protocol (exercise and diet); Cristina W. Nogueira: supervised the experiments and revised the final version of the manuscript.

\section{(cc) BY}

